\title{
PATOLOGIA NAS FUNDAÇÕES DE ESTRUTURAS DE CONCRETO: GÊNESE DAS FISSURAS NAS ESTRUTURAS
}

\author{
PATHOLOGY IN FOUNDATIONS OF CONCRETE STRUCTURES: GENESIS \\ OF CRACKS IN STRUCTURES
}

\begin{abstract}
Kamilla Nayara Batiston - kamilla.batiston@hotmail.com
Walter Gonçalves Ferreira Filho - gferreira05@gmail.com

Uniara - Universidade de Araraquara -Araraquara -São Paulo -Brasil
\end{abstract}

https://doi.org/10.47820/recima21.v2i10.940

\begin{abstract}
Resumo
Atualmente, com a tecnologia disponível, os problemas patológicos das estruturas de concreto armado são tratados com maior precisão. Esse tipo de contratempo nem sempre é motivado por desgaste pelo tempo de uso da construção. Às vezes ocorre devido a falhas durante as fases da obra: no projeto, na execução ou na posterior utilização quando concluída. Entender e saber diagnosticar o problema patológico no concreto armado é tão necessário quanto saber evitar que o desgaste aconteça. Este trabalho teve como objetivo conhecer as principais causas que dão origem a essa adversidade, tanto quanto saber sobre a natureza do defeito que pode comprometer toda uma estrutura. Esse conhecimento específico adquirido através de consulta bibliográfica, sobre os processos destrutivos e sobre equipamentos e técnicas de observação, visa facilitar um diagnóstico sobre a maioria dos problemas patológicos. É fundamental para o profissional da área saber sobre as medidas preventivas no desenrolar do projeto, assim como a forma de aplicação de medidas saneadoras se o problema acontecer.
\end{abstract}

Palavras-chave: Concreto Armado. Desgaste. Estrutura. Problemas Patológicos.

\begin{abstract}
Nowadays, with the technology available, the pathological problems of the reinforced concrete structures are treated with greater precision. This type of setback is not always motivated by wear and tear by the time of use of the construction. Sometimes it occurs due to failures during the phases of the work: in the design, in the execution or in the later use when completed. Understanding and knowing how to diagnose the pathological problem in reinforced concrete is as necessary as knowing how to prevent wear and tear from happening. This work aimed to know the main causes that give rise to this adversity, as well as to know about the nature of the defect that can compromise an entire structure. This specific knowledge acquired through bibliographical consultation on destructive processes and observation equipment and techniques aims to facilitate a diagnosis of most pathological problems. It is fundamental for the professional in the field to know

${ }^{1}$ Graduando no Curso Bacharelado de Engenharia Civil - Kamilla Nayara Batiston ${ }^{2}$ Orientador(a) Docente do curso Engenharia Civil - Walter Gonçalves Ferreira Filho.
\end{abstract}


about preventive measures in the course of the project, as well as how to apply sanitation measures if the problem happens.

Key-words: Armed Concrete. Wear. Structure. Pathological Problems.

\section{INTRODUÇÃO}

Hoje em dia existe considerável preocupação com a estabilidade e a segurança nas construções, o que levou ao maior desenvolvimento tanto dos materiais usados, como de métodos e técnicas utilizadas no andamento de projetos, que agora abrangem cálculos mais aprofundados, principalmente no detalhamento das suas estruturas. A evolução tecnológica implantada na construção civil, notadamente sobre patologia das estruturas de concreto armado, tem gerado muito interesse entre profissionais do ramo. (EVOLUÇÃO, 2021)

No entanto os chamados "problemas patológicos" ocorrem e não apenas em estruturas antigas. Embora também se analise a possibilidade da degradação das estruturas ser resultado do envelhecimento natural do material usado, ou pela falta de manutenção adequada, outras razões são citadas como responsáveis pelo surgimento das manifestações patológicas, como: erros primários na elaboração do projeto; escolha equivocada do material usado na construção e falta de mão de obra qualificada para operar nas diferentes etapas da obra. Em grande parte dos laudos conclusivos sobre a ocorrência de problemas patológicos, em qualquer uma das fases da construção, a imperícia humana acaba sendo considerada como responsável.

O objetivo principal da escolha referente ao tema segue a predisposição de estudar mais detalhadamente as origens e formas de manifestação patológica em estruturas de concreto armado, para complementação dos conhecimentos sobre esses processos destrutivos e sobre as formas de se lidar com o problema.

O interesse se justifica por entender que a soma do conteúdo já adquirido, aliada as noções disponibilizadas em obras específicas e pesquisadas para este fim, deve permitir um diagnóstico mais preciso a respeito dos problemas patológicos que possam surgir no cotidiano das obras, facilitando para detectar as causas, conceber medidas preventivas e também na escolha de ações para recuperação de dano. 
A metodologia escolhida consistiu em ampla pesquisa e consulta bibliográfica às obras específicas sobre o tema disponibilizadas aos interessados, estudantes e profissionais de Engenharia.

O objetivo do trabalho é apresentar a patologia nas fundações de estruturas de concreto: gênese das fissuras nas estruturas.

O tema se desenvolve em capítulos, onde após a Introdução é apresentada uma breve análise dos antecedentes da construção, seguido por um levantamento sobre o conceito de patologia na engenharia que, pela amplitude do assunto, se estende às subseções investigação e diagnóstico de causas patológicas; fases do surgimento de problemas patológicos e áreas de localização das manifestações patológicas.

A seguir, especificamente sobre o tema, a análise ocorre no capítulo: concreto armado: constituição e deteriorização.

Nas Considerações Finais a autora expõe sua conclusão sobre o tema.

\section{ANTECEDENTES DA CONSTRUÇÃO}

Pesquisar sobre a história da engenharia civil através das construções erguidas desde a pré-história é rever a história da humanidade, visto que o ato de construir está intrinsecamente ligado às necessidades humanas de proteção em seu habitat natural. É preciso analisar vários aspectos desde o uso de materiais até a aplicação de técnicas de construção, sem deixar de considerar as demonstrações culturais expressas pelas diversas civilizações constituídas através dos séculos.

Segundo Oliveira et al, desde os primórdios da vida humana existiu a procura por abrigos seguros contra intempéries e ataques de animais. Um perigo que era ocasionalmente afastado pelo costume tribal de se esconder em grutas ou cavernas naturais que, no entanto, nem sempre eram acessíveis, existiam ou estavam desabitadas.

O homem começou por se recolher em abrigos naturais como cavernas e grutas para se proteger do clima e dos animais. Em algumas partes do país, encontram-se abrigos com paredes de pedra, mas cuja cobertura é em materiais vegetais, e que se podem também considerar 
uma forma morfológica e cronologicamente primária de habitação (OLIVEIRA et al 1969: 28, 2021).

Depois veio a utilização de rústicas ferramentas e a busca na Natureza de elementos para construções que permitissem maior segurança individual e da prole ou grupo.

Em relação ao uso diversificado de materiais constatado na História das Construções, têm-se a argumentação de Hugon de que "os materiais variam segundo as épocas, segundo os recursos locais, segundo os meios de transporte e realização, segundo a estética, etc". (2004:1, 2021)

Partindo da premissa de que numa obra um dos principais elementos da estrutura é a fundação, e pressupondo que esse raciocínio seja resultante da capacidade de observação do homem primitivo na escolha de materiais mais resistentes para sua obra, Nápoles Neto diz que "no Neolítico, quando o homem que na idade anterior já aprendera a lascar a pedra, e, agora sedentário, construiu suas primeiras cabanas, já tivesse alguma noção empírica sobre a resistência e a estabilidade dos materiais" (1998:17, 2021).

Segundo o citado autor, podem ser classificados "cinco principais materiais primários de construção: madeira, rocha, aço, concreto e solo"

No período Neolítico, as choupanas construídas eram todas de madeira, sendo que cabanas de pedra eram mais raras, existindo apenas em locais onde não havia madeira ou em locais com intemperismo intenso. [...] Nos antigos impérios do Oriente Próximo, os materiais de construção passaram a ser o tijolo cerâmico e a pedra, aquele na Mesopotâmia e está no Egito. (NÁPOLES NETO, 1998:17, 2021)

Além da pedra e da madeira, certamente as primeiras opções de matéria prima utilizadas nas construções humanas, também os metais foram usados pelo homem primitivo.

Deles o primeiro deve ter sido o cobre seguido pelo ferro encontrado muito facilmente e com muita abundância em determinadas regiões do mundo e do qual sobrevivem até os nossos dias muitos exemplares de utensílios que comprovam seu uso em larga escala.

Não se sabe exatamente quando começou na humanidade o uso de metais. Há evidências de que isso tenha ocorrido acidentalmente, no período final da era neolítica, próximo de 4000 a.C. O mais antigo metal conhecido é o cobre, tendo sido encontrado nas habitações lacustres 
de Robenhausen, na Suíça, em 6000 a.C., na Mesopotâmia préhistórica, em 4500 a.C., no Egito em 4000 a.C., nas ruínas de Ur e nos Mound-Builders da América do Norte. (Durant, 1963 apud DIAS, 2001:9, 2021)

Foi a fixação dessas populações em diversas regiões do planeta que provocou o aumento das edificações e com uso de recursos diferentes, aproveitando o que a natureza local facilitava ao homem em seus projetos.

Essa variedade na criatividade humana tem como ponto comum o interesse por elementos que, além da facilidade de obtenção, também oferecessem mais resistência e durabilidade.

No entendimento de Vargas (1998:34), em relação ao Brasil a história das construções teve início na época da colonização, época em que existiram três tipos específicos de construções:

1) as edificações que atendiam as necessidades econômicas relacionadas a cultura da cana de açúcar, sua industrialização e instalações portuárias para a exportação;

2) as construções para uso público e de segurança como fortalezas, instalações militares, quartéis, cadeias, edifícios públicos,

3) as obras civis como casas de moradia, igrejas, casas comerciais, moinhos e armazéns.

"Nesses edifícios dominavam as técnicas locais de taipas, tanto de paua-pique, como de pilão" (VARGAS, 1998:34, 2021).

\begin{abstract}
Antes que alcançasse o desenvolvimento que tem hoje, foi preciso que a engenharia civil percorresse um longo trajeto de seis mil anos desde que o homem deixou as cavernas e começou a pensar numa moradia mais segura e confortável. Já os templos, os palácios e os canais, que foram marca registrada na Antiguidade, começaram a fazer parte da paisagem cerca de dois mil anos depois do aparecimento das primeiras habitações familiares. (RIELI, 2012:1).
\end{abstract}

Vargas (1998:36) argumenta que "com o advento do concreto armado, nas primeiras décadas do nosso século, a situação começa a modificar-se, pois o concreto armado permite já edifícios altos de cargas concentradas".

Dessa constante experimentação, através dos milênios, própria da evolução natural do progresso humano, apareceu nos tempos modernos a maior preocupação com a estabilidade e segurança nas construções. Fato que nos dias de hoje, devido a necessidade econômica, exige maior responsabilidade quanto aos custos das obras. 
O setor da construção civil é um dos mais importantes alicerces econômicos do país. [...] Em nível de qualidade, exige-se para a etapa de concepção, a garantia de plena satisfação do cliente, de facilidade de execução e de possibilidade de adequada manutenção; para a etapa de execução, será de garantir o fiel atendimento ao projeto, e para a etapa de utilização, é necessário conferir a garantia de satisfação do utilizador e a possibilidade de extensão da vida útil da obra (SOUZA e RIPPER, 1998:22, 2021).

Com mais formas de uso dos materiais e com aumento das técnicas e métodos utilizados, se convencionou existir a aplicação de tecnologia própria para a construção civil. Surgiram novas ideias, conceitos, utilização de diferentes materiais naturais e, principalmente, normas únicas e padronizadas para o trabalho nesse segmento.

Por essa razão, o essencial é a tecnologia que consiste na análise, cálculo e detalhamento das estruturas e respectivas formas construtivas.

\section{CONCEITO DE PATOLOGIA NA ENGENHARIA}

Segundo o dicionário on-line MICHAELIS, Patologia é um substantivo que vem do grego pathos com significado de doença ou sofrimento, somado ao sufixo logia que significa ciência ou estudo.

pa.to $\cdot$ lo gi $\cdot a$

sf

MED Ciência que estuda todos os aspectos da doença, com especial atenção à origem, aos sintomas e ao desenvolvimento das condições orgânicas anormais e suas consequências.

ETIMOLOGIA

der do voc comp do gr páthos+gr lógos+ia1, como fr pathologie.

No conceito médico significa a ciência que estuda a origem, sintomas e natureza das doenças. Na engenharia ela também recebe a denominação de Patologia e é considerada como ciência ligada às construções.

Designa-se genericamente por PATOLOGIA DAS ESTRUTURAS esse novo campo da Engenharia das Construções que se ocupa do estudo das origens, formas de manifestação, consequências e mecanismos de ocorrência das falhas e dos sistemas de degradação das estruturas (SOUZA e RIPPER, 1998:14, 2021). 
$\mathrm{Na}$ Patologia das Construções é analisada a origem, manifestações e consequências do erro em obras, obtendo definição do problema através do estudo das anomalias provenientes de lesão, defeito, falha ou dano que aconteça em uma construção, a chamada manifestação patológica, forma correta de designar o mecanismo de degradação que esteja acontecendo.

O problema de manifestação patológica em edificações se tornou muito recorrente gerando maior atenção e, em consequência, opiniões diversas e várias definições:

A patologia na execução pode ser consequência da patologia de projeto, havendo uma estreita relação entre elas; isso não quer dizer que a patologia de projeto sendo nula, a de execução também o será. Nem sempre com projetos de qualidade desaparecerão os erros de execução. Estes sempre existirão, embora seja verdade que podem ser reduzidos ao mínimo caso a execução seja realizada seguindo um bom projeto e com uma fiscalização intensa. (CANOVAS, 1998:111, 2021)

O concreto armado é um recurso muito utilizado na construção civil, mas cuja execução desde a concepção do projeto até a manutenção das edificações, nem sempre é usada com a devida atenção ao cumprimento de regras básicas.

Esse descuido gerou, inclusive, uma designação própria para a manifestação, como explica Helene (1992, in CAVACO, 2008:10, 2021):

Entende-se por patologia do concreto armado a ciência que estuda os sintomas, mecanismos, causas e origens dos problemas patológicos encontrados nas estruturas de concreto armado. Lembrando que para um dano qualquer, existe a possibilidade de vários fatores serem responsáveis. Estes danos podem vir apenas a causar incômodos para aqueles que irão utilizar a obra segundo o fim para que foi feita, tais como pequenas infiltrações até grandes problemas que podem levar a estrutura ao colapso.

É fato que o avanço tecnológico aconteceu em muitas das áreas da sociedade humana. A Engenharia seguiu como tantas outras em evidente evolução, mas apesar disso, tem sido comum registrar-se tanto em obras públicas como nas residenciais, muitas manifestações patológicas em estruturas de concreto armado. 
receba manutenção sistemática e programada, há construções que apresentam manifestações patológicas em intensidade e incidência significativas, acarretando elevados custos para sua correção. Sempre há comprometimento dos aspectos estéticos e, na maioria das vezes, redução da capacidade resistente, podendo chegar, em certas situações, ao colapso parcial ou total da estrutura.

O concreto, apesar de apresentar constância nas manifestações patológicas, é preferência nas construções, chegando a ser considerado por alguns como um material de duração eterna.

Mas, nem sempre é visto assim, conforme opinam Souza \& Ripper para quem "as estruturas de concreto não são eternas, pois se deterioram com o passar do tempo e não alcançam sua vida útil se não são bem projetadas, executadas com esmero, utilizadas com critério e, finalmente, submetidas a uma manutenção preventiva" (1998: prefácio).

\subsection{INVESTIGAÇÃO E DIAGNÓSTICO DE CAUSAS PATOLÓGICAS}

"Na análise das patologias das edificações em diversos casos existentes na engenharia legal, o profissional deverá analisar cada item construtivo detectando a origem da patologia e sua extensão" (DEUTSCH, 2011:127, 2021).

Para diagnosticar uma manifestação patológica na construção é necessário que seja aplicada metodologia e técnica, começando pela revisão do projeto desenvolvido e fazendo avaliação sobre se houve real cumprimento das especificações técnicas nele e nos memoriais descritivos.

Em seguida, uma avaliação mais técnica é feita com testes e análises nas estruturas, fundações e revestimentos para verificação quanto ao uso, maneira como foi operado e como se dá a manutenção do objeto da análise.

Conforme Souza e Ripper (1998:14):

o surgimento de problema patológico em dada estrutura indica, em última instância e de maneira geral, a existência de uma ou mais falhas durante a execução de uma das etapas da construção, além de apontar para falhas também no sistema de controle de qualidade próprio a uma ou mais atividades.

Exceto em raros casos, em geral os problemas patológicos demonstram externamente uma manifestação característica do dano, a partir da qual se chega a dedução da natureza, origem e dos próprios mecanismos envolvidos 
nas manifestações permitindo, inclusive, a estimativa sobre as prováveis consequências da falha.

Após a implantação do Código de Defesa do Consumidor, lei promulgada em 11 de setembro de 1.990, apareceu grande quantidade de demandas judiciais envolvendo consumidores (proprietários) e construtoras.

O Código tem abrangência em várias esferas das relações de consumo, como civil, ao definir as responsabilidades e respectivos mecanismos reparadores do dano; na área administrativa, ao detalhar mecanismos de atuação do poder público frente as relações de consumo; e no aspecto penal, estabelecendo tipos novos de crime e respectivas penalidades para os mesmos.

Desde então se tornou ainda mais necessário ter conhecimento sobre a origem do problema, visto que para fins judiciais a identificação sobre quem cometeu a falha é essencial.

[...] é altamente recomendável que os patologistas da construção
façam uma investigação completa do problema analisado, para
identificar suas causas, o que implica em percorrer toda a metodologia
clássica investigatória, desde a anamnese do problema, após a
evidenciação da sintomatologia para verificar se o problema é
localizado ou generalizado, e assim poder definir a extensão do exame,
fazer o levantamento de subsídios investigativos, que possam conduzir
ao entendimento dos mecanismos de surgimento dessas patologias
(GRANDISKI, 2011:127, 2021).

Por exemplo, uma fissura não é uma patologia e sim um sintoma cujo mecanismo de degradação, a chamada doença, pode ser resultante da corrosão de armaduras, deformação excessiva da estrutura, reação álcali-agregado, ou outra, mas cuja terapia, ou seja, a forma de restauração da estrutura (conserto) deve levar em conta as causas da doença.

Para a definição do problema é feita completa análise, avaliando o desgaste, a falha e anomalias que existam, segundo uma classificação de irregularidades que devem apontar a provável origem do problema patológico.

"As patologias em edificações podem ter origens diferenciadas. Fatores endógenos, exógenos, funcionais e naturais podem interferir na edificação gerando problemas diversos" (DEUTSCH, 2011:127, 2021).

Essa origem pode acontecer no próprio projeto, na execução do mesmo, quanto a forma de operação e uso, assim como na manutenção feita de forma inadequada. 
[...] a ocorrência de problemas patológicos cuja origem está na etapa de execução é devida, basicamente, ao processo de produção que é em muito prejudicado por refletir de imediato os problemas socioeconômicos, que provocam baixa qualidade técnica dos trabalhadores menos qualificados, como os serventes e os meiooficiais, e mesmo do pessoal com alguma qualificação profissional (BOTELHO 2004, p.43, 2021).

Do diagnóstico deve constar de maneira clara e objetiva a identificação da natureza, causa e origem do desgaste, extraído do maior número de informações e provas materiais colhidas junto a obra, em exames de caráter visual, estudos laboratoriais e de anotações de canteiro e das reuniões durante a execução do projeto. Assim como a orientação técnica quanto ao possível reparo e seu respectivo custo.

Grandiski (2011:127) considera da seguinte forma as causas que dão origens aos problemas patológicos:

Origem Exógena - causas com origem fora da obra e provocadas por fatores produzidos por terceiros, ou pela natureza.

Origem Endógena - causas com origem em fatores inerentes à própria edificação.

Origem na Natureza - causas que podem ser falhas previsíveis ou imprevisíveis, evitáveis ou invitáveis, conforme o caso.

No entanto, para a maioria dos autores, os problemas patológicos só se manifestam após o início da obra propriamente dita e, em geral, na última fase da produção.

No entender de Helene (1986:23),

Os fenômenos patológicos geralmente apresentam manifestação externa característica, a partir da qual se pode deduzir a natureza, a origem e os mecanismos dos fenômenos envolvidos. Certas manifestações têm maior incidência, devido a necessidade de cuidados que frequentemente são ignorados, seja no projeto, na execução ou até mesmo na utilização. Pode-se dizer que os problemas patológicos de maior gravidade nas estruturas em concreto armado, notadamente pelo seu evidente risco à integridade da estrutura, são a corrosão da armadura do concreto, as flechas excessivas das peças estruturais e as fissuras patológicas nestas. 


\subsection{FASES DO SURGIMENTO DE PROBLEMAS PATOLÓGICOS}

As manifestações patológicas estruturais podem surgir nas seguintes fases: na etapa do projeto, durante a execução da obra e na utilização da edificação.

Um problema patológico normalmente resulta em aumento de custo para a obra, por isso quanto mais rápido for percebido, menor é o montante a ser gasto para a recuperação do dano e mais rapidamente é encontrada a solução para o reparo da falha, o que, indiscutivelmente, reduz o gasto com a falha.

Deduz-se, pois, que os problemas patológicos podem se originar desde a fase de projeto, passando pela etapa da construção e chegando a fase de utilização da edificação, após o término da construção.

\section{FALHA DE CONCEPÇÃO DA ESTRUTURA (ETAPA DO PROJETO)}

No caso de falha oriunda do próprio projeto, ou etapa preliminar, é classificada como onerosa e de maior dificuldade técnica, principalmente em função da complexidade que sua solução requer. O valor do reparo, nesse caso, é calculado de acordo com a rapidez para a solução ser encontrada e transformada em ação reparadora.

Falhas patológicas com origem na fase do projeto são definidas por Santos (2014:4) segundo erros como:
a) falta de detalhes;
b) erros de dimensionamento;
c) não consideração do efeito térmico;
d) divergência entre os projetos;
e) sobrecargas não previstas;
f) especificação do concreto deficiente;
g) especificação de cobrimento incorreta.

Em geral esse tipo de falha é decorrente de um estudo preliminar descuidado ou deficiente que dá origem a anteprojetos equivocados. O resultado é o encarecimento da obra como um todo, além do aparecimento de transtornos relacionados até com a utilização da obra.

FALHA NA EXECUÇÃO DA ESTRUTURA (DURANTE A CONSTRUÇÃO) 
"No sistema estrutural os esforços são distribuídos nas peças: vigas, lajes e pilares. As principais anomalias que são detectadas se apresentam sob a forma de trincas e fissuras" (DEUTSCH, 2011:128, 2021).

A etapa subsequente ao projeto é a da execução da obra, ou seja, a colocação do planejamento em prática. É fase de maior envolvimento com operadores (funcionários) que nem sempre são devidamente qualificados e deve ser cercada de cuidados extras para bom gerenciamento do trabalho, a começar com a correta distribuição do canteiro de obras; uma programação de atividades constantemente observada e conferida, além de previsão de compras.

Também nessa etapa, após o início da construção, ocorrem falhas que podem se originar de diversas formas desde as condições inadequadas de trabalho e mão de obra desqualificada, independente da categoria profissional (braçal ou técnico); até falta de controle de qualidade, material de má qualidade e irresponsabilidade técnica.

Para Souza e Ripper (1998:25) nessa fase podem ocorrer os seguintes erros:
a) falta de condições locais de trabalho (cuidados e motivação);
b) não capacitação profissional de mão de obra;
c) inexistência de controle de qualidade de execução;
d) má qualidade de materiais e componentes;
e) irresponsabilidade técnica;
f) sabotagem.

Normalmente as falhas dessa fase de execução devem-se ao processo de produção. Basicamente são reflexos de crise socioeconômica, em que as finanças obrigam ao barateamento da construção e são feitas medidas de contenção de gastos com escolhas de pouca qualidade técnica na mão de obra, não apenas em trabalhadores menos qualificados, mas inclusive na equipe com necessária qualificação profissional.

\section{FALHA NO USO DA ESTRUTURA (MANUTENÇÃO DO EDIFÍCIO)}

A ausência de manutenção ou mesmo quando ela é feita de forma inadequada, pode originar manifestações patológicas estruturais. A manutenção periódica da estrutura deve ser rigorosamente observada, principalmente em áreas de maior uso, tanto quanto as suscetíveis de desgaste, para evitar problemas patológicos sérios que podem resultar inclusive na ruína da estrutura. 
O correto uso da estrutura, segundo a intenção para o qual foi projetada, é a melhor garantia de bom desempenho da mesma, principalmente em relação aos carregamentos e evitando materiais onde constem elementos agressivos ao concreto armado, pois o uso inadequado, mudando a finalidade da construção, é muito prejudicial para sua durabilidade.

Segundo Souza e Ripper (1998:27)

de certa forma uma estrutura poderá ser vista como um equipamento mecânico que, para ter sempre bom desempenho, deve ter manutenção eficiente, principalmente em partes onde o desgaste e a deterioração serão potencialmente maiores.

Olivari (2003:8 in SANTOS, 2014:5) argumenta que alguns sintomas evidentes de problemas patológicos estruturais como fissuras e trincas em elementos estruturais e alvenarias; esmagamento do concreto; desagregação do concreto; disgregação do concreto (ruptura); carbonatação; corrosão da armadura; percolação de água; manchas, trincas e descolamento de revestimento em fachadas, tem como causas: recalque das fundações; movimentação térmica; excesso de deformação das peças estruturais; sobrecargas ou acúmulo de tensões; retração do cimento; carbonatação; expansão de armadura (corrosão) e reações químicas internas.

\section{4. ÁREAS DE LOCALIZAÇÃO DAS MANIFESTAÇÕES PATOLÓGICAS}

ALVENARIAS - um dos locais de manifestação patológica comuns em construção, no entender de Deutsch (2011:133) "são os elementos de vedação utilizados para definir os compartimentos e ambientes de uma edificação".

As alvenarias podem acontecer nas estruturas ou na vedação, unidas por um tipo de argamassa, sejam em paredes revestidas ou não. Entre elas as principais são as fissuras das quais as principais causas para Santos (2014:5) são: “a) a movimentação térmica; b) a movimentação higroscópica; c) o movimento das fundações; d) as deformações das estruturas de concreto armado". 
De acordo com Deutsch (2011:135) quase todos os casos de fissuras em alvenarias estruturais ou não, são resultantes de tensões de tração e cisalhamento...

e aparecem na região de encunhamento, nos encontros entre alvenaria e estrutura, no encontro de paredes, na base de paredes provenientes de problemas de impermeabilização ou lençol freático, na parte superior de muros e peitoris que não estejam convenientemente protegidos por rufos.

Segundo Santos, algumas manifestações patológicas em alvenarias que também ocorrem são "os desplacamentos, as eflorescências e as criptoeflorescências".

Criptoeflorescências são formações salinas ocultas com o crescimento de sais no interior dos materiais, entre a alvenaria e o acabamento, um fenômeno que acarreta a desagregação e o descolamento dos elementos construtivos. (SANTOS, 2014:5, 2021)

ACABAMENTOS - um sistema de edificação basicamente se compõe de estrutura, vedação e revestimento. É exatamente no revestimento que costumam aparecer as manifestações patológicas tanto da estrutura ou vedação, quanto do próprio revestimento.

"A principal função dos acabamentos é a de proteção dos elementos estruturais e alvenarias de vedação. Os acabamentos protegem as edificações das intempéries, aumentando sua vida útil e desempenho" (DEUTSCH, 2011:135, 2021).

Conforme explica Santos (2014:6) nas edificações pode ser observado os seguintes fenômenos, que prejudicam o aspecto das paredes e tetos:

a) pintura encontra-se parcial ou totalmente fissurada, deslocando da argamassa de revestimento;

b) existência de formação de manchas de umidade, com desenvolvimento de bolor;

c) existência de formação de eflorescência na superfície da tinta ou entre a tinta e o reboco;

d) a argamassa do revestimento descola inteiramente da alvenaria, em placas compactas ou por desagregação completa;

e) a superfície do revestimento apresenta fissuras de conformações variada;

f) a superfície do revestimento apresenta vesículas com deslocamento da pintura;

g) o reboco endurecido empola progressivamente, deslocando do emboço. 
O citado autor explica que as causas dessas ocorrências sobre a argamassa de revestimento acontecem pelo tipo e qualidade dos materiais utilizados no preparo da argamassa de revestimento; mau proporcionamento das argamassas; c) má aplicação de revestimento; d) fatores externos ao revestimento" (SANTOS, 2014:6, 2021).

Essas manifestações patológicas que ocorrem nos Acabamentos podem ocorrer em duas situações: nas argamassas e nos revestimentos cerâmicos.

\begin{abstract}
A base que receberá os revestimentos deverá ser corretamente especificada e preparada, para se evitarem problemas de falta de aderência, entre outros. As argamassas, assim como o concreto, também são plásticas nas primeiras horas, e endurecem com o tempo, ganhando elevada resistência e durabilidade. A correta especificação da dosagem é essencial para um bom desempenho e trabalhabilidade. Para se obter uma boa trabalhabilidade é importante a adição de aditivos plastificantes e incorporadores de ar (DEUTSCH, 2011:136, 2021).
\end{abstract}

Para Santos (2014:6) nas argamassas os principais sintomas das manifestações patológicas são:
a) manchas de umidade e mofo;
b) descolamento da argamassa do substrato;
c) aparecimento de bolhas;
d) aparecimento de fissuras;
e) retrações - ocorrem quando a argamassa seca muito rapidamente; um reboco em parede muito ensolarada deverá ser mantido úmido por no mínimo três dias, adquirindo resistência as tensões de secagem;
f) pulverulência - excesso de finos nos agregados ou traço pobre.

Em relação aos revestimentos cerâmicos os sintomas dos problemas podem ocorrer apenas na fase da execução, ou se originar desde a etapa do projeto, quando da escolha do material ou se o autor do projeto ignorar a necessidade de interação entre revestimento e demais partes da construção como esquadrias, estruturas, etc.

Segundo Santos (2014:6-7) os sintomas de manifestações patológicas em revestimento são diferentes em pisos e paredes:

\title{
PISOS
}

a) Caimento inadequado; b) manchas decorrentes da umidade ascendente; c) deficiência de impermeabilização; d) eflorescências; e) descolamentos e destacamentos.

\section{PAREDES OU FACHADAS}

a) descolamentos e destacamentos das placas; b) trincas, gretamento e fissuras; c) eflorescências; d) deterioração das juntas; e) bolor. 
PINTURAS - a característica da pintura é ser um revestimento que fornece um acabamento estético, além de dar proteção aos elementos construtivos e aumentar a durabilidade da construção.

Segundo Deutsch (2011:139) "As tintas são utilizadas para proteção e acabamento de superfícies das mais diversas características. São composições líquidas ou pastosas capazes de formar filmes após a secagem ou cura."

O processo de pintura de uma construção requer materiais que possuam as seguintes características: facilidade de aplicação, estabilidade de cor, conservação da aparência, bom rendimento, poder de cobertura, resistência a agentes agressivos (água, fungos, radiação solar, poluentes).

Para Santos (2014:7) são usados os seguintes materiais de acordo com a área a ser pintada:

a) para argamassa, concreto ou cerâmica - usa-se tintas látex PVA, látex acrílico, caiação, à base de cimento, esmalte sintético, resina epóxi e borracha clorada; vernizes poliuretanos e acrílicos; silicones;

b) para madeiras - tintas à óleo e esmalte sintético; vernizes;

c) para metais - tintas à óleo e esmalte sintético.

A não observância dessas medidas pode acarretar no surgimento das seguintes manifestações patológicas:

a) Aparecimento de trincas: geralmente ocorre com a movimentação natural da estrutura da edificação e da natural expansão do concreto.

b) Aparecimento de bolhas: decorrente do uso de massa corrida PVA em superfícies externas. As bolhas também podem surgir quando há uma repintura sobre uma tinta muito antiga ou de qualidade inferior.

c) Eflorescências: manchas que aparecem quando aplica-se a tinta diretamente sobre o reboco úmido ou por ação de infiltrações.

d) Descascamento: ocorre quando se aplica a tinta em superfícies pulverulentas ou que tiveram aplicação de cal, dificultando sua aderência na base.

e) Enrugamento: ocorre quando há uma excessiva quantidade de tinta numa demão ou quando não é respeitado o tempo de secagem correto entre demãos.

f) Saponificação: ocorre pela alcalinidade natural da cal e do cimento que constituem o reboco.

g) Calcinação: decorrente da alcalinidade natural da cal e do cimento e são provenientes das condições do intemperismo natural, principalmente pelas águas das chuvas.

h) Desagregamento: acontece quando se aplica a tinta sobre um reboco novo, não curado ou na presença da umidade. 
i) Descolamento: acontece na repintura de superfícies, que devem estar em boas condições para receber novas demãos de tinta.

j) Descoloração: ocorre quando, com o tempo, a superfície pintada vai perdendo seu brilho ou intensidade. A lua solar sobre esta superfície acelera este processo.

k) Cratera: aparece quando as tintas utilizadas são diluídas em solventes não indicados ou devido à contaminação da superfície por graxas, silicones.

I) Manchas brancas: são decorrentes da presença de umidade na superfície de aplicação.

m) Manchas: Aparecem devido à ação de respingos de chuva, de fungos e também por ação de infiltrações. (SANTOS, 2014:7)

UMIDADE - uma grande responsável por muitos dos problemas patológicos encontrados nas edificações.

\begin{abstract}
A umidade é o maior inimigo das construções e da saúde dos seus ocupantes. E é justamente contra este mal que não se tomam muitos cuidados nas obras, por falta de conhecimentos das soluções corretas ou por falta de senso de responsabilidade, partindo-se para soluções mais baratas, mesmo por simples negligência do pessoal encarregado da execução. É de se admirar que justamente em regiões como a nossa, onde são frequentes chuvas em grandes quantidades e intensidades, notam-se frequentemente falhas neste particular. Principalmente nas residências, não é bem cuidada a proteção da alvenaria e dos pisos, contra a umidade, a negligência no tratamento dessa proteção é como que um crime contra a saúde dos ocupantes. (RIPPER, 1984:42).
\end{abstract}

Para garantir a qualidade quando da utilização da construção, o melhor é prevenir a possibilidade do seu aparecimento eliminando condições que sejam favoráveis a ela.

Segundo Souza (2008:8) "na construção civil, os defeitos mais comuns são decorrentes da penetração de água ou devido à formação de manchas de umidade". Para esse autor, os problemas gerados por umidade são graves, de difícil solução e causam "a) prejuízos de caráter funcional da edificação; b) desconforto dos usuários e em casos extremos os mesmos podem afetar a saúde dos moradores; c) danos em equipamentos e bens presentes nos interiores das edificações; d) diversos prejuízos financeiros".

Para Verçoza (1985:11) "Nas construções, os defeitos de impermeabilização podem causar os seguintes problemas: goteiras, manchas, mofo, apodrecimento, ferrugem, eflorescências, criptoflorescências, gelividade e deterioração".

Ainda nesse assunto, Santos, na revista Especialize (2014:8) afirma que: 
a) As goteiras são provenientes de águas das chuvas e/ou da ocorrência de vazamentos ou infiltrações em marquises, terraços, floreiras;

b) As manchas são o resultado da saturação de água em um devido local;

c) O mofo é resultante de fungos vegetais que ocasionam a deterioração dos materiais empregados na edificação, da madeira e até mesmo da alvenaria;

d) Bolores são fungos que vivem de matérias orgânicas por eles decompostas.

e) Oxidação é o processo químico que acontece em um metal que permaneceu sujeito à umidade. No caso de ferro e aço, a oxidação toma o nome de ferrugem. Quando esse fenômeno ocorre em aço é denominado de ferrugem e provoca o aumento de volume das barras. Então a consequência é a desagregação do recobrimento das barras; f) Eflorescências são formações de sais que aparecem sob o aspecto de manchas de cor branca e que foram transportados pela umidade. Muito comum em paredes de tijolos. Quando situadas entre o reboco e a parede, as eflorescências forçam um plano capilar, por onde sobe a umidade, que aumenta a força de repulsão ao reboco. É normal que as pinturas não eliminem essas manchas, que voltam a aparecer. O ideal é remover o reboco atacado;

g) As criptoflorescências são patologias formadas também de sais solúveis, porém diferem das eflorescências por apresentarem a formação de grandes cristais que se fixam no interior da própria parede ou estrutura, provocando, desta forma, o aumento de volume, pressionando a massa, formando rachaduras;

h) Gelividade é o fenômeno que acontece quando a água que existe dentro dos materiais porosos congela devida a uma baixa temperatura, mas o pior efeito é na superfície onde a resistência é menor;

i) Deterioração é o processo causado por todos os defeitos citados acima, onde tais defeitos vão aos poucos deteriorando os materiais e a obra construída.

Souza, (2008:8) lembra ainda que "os problemas de umidade podem se manifestar em diversos elementos das edificações - paredes, pisos, fachadas, elementos de concreto armado, etc. Geralmente eles não estão relacionados a uma única causa".

IMPERMEABILIZAÇÕES - considerando que impermeabilizar algo, seja um objeto ou um espaço físico, é torná-los protegidos contra a água ou qualquer outro líquido de forma que estes não consigam penetrar no material impermeabilizado, se a ação não for desenvolvida seguindo os requisitos técnicos específicos para tal, podem ocorrer sérios danos de infiltração.

Embora no mercado de construção estejam disponíveis materiais seguros e de comprovada qualidade técnica na impermeabilização, dentro das normas específicas da Associação Brasileira de Normas Técnicas (ABNT) e conforme o Instituto Brasileiro de Impermeabilização (IBI), nem sempre esses requisitos são utilizados pelas construtoras. 
A adoção de práticas precárias, ausência de projeto específico e uso de produtos não dotados de requisitos técnicos e de qualidade, resultam em prejuízo financeiro para o construtor e ao próprio consumidor final, além de graves problemas patológicos.

O projeto desenvolvido na engenharia deve ter soluções de impermeabilização com orçamentos unificados para serviços, em conjunto com outras áreas como Arquitetura e Paisagismo, considerando todas as interferências geradas na obra.

O projeto deve ser desenvolvido em conjunto e compatibilizado com os demais projetos de construção, tais como arquitetura (projeto básico e executivo), estrutural, hidráulico-sanitário, águas pluviais, gás, elétrico, revestimento, paisagismo e outros, de modo a serem previstas as correspondentes especificações em termos de tipologia, dimensões, cargas, ensaios e detalhes construtivos (NBR 9575, 2010, 2021).

Para Deutsch (2011:149) "impermeabilizar superfícies horizontais e verticais nas edificações é prevenir a penetração d'água nos seus elementos estruturais e arquitetônicos".

\begin{abstract}
A impermeabilização deve ser projetada e executada devidamente onde é necessária a: proteção de construções abaixo do nível freático, tipo sub-solos e muros de arrimo; proteção da alvenaria contra umidade do solo e contra respingos; proteção das lajes de pisos dos chuveiros e também de suas paredes; proteção das lajes de cobertura, dos terraços das marquises e floreiras; proteção de caixas e reservatórios subterrâneos e elevados, etc. (SANTOS, 2014:10, 2021)
\end{abstract}

As normas principais sobre a ação impermeabilizante são: NBR 9574:2008 referente a Execução de impermeabilização e a NBR 9575:2010 sobre Seleção e Projeto.

Conforme a NBR 9575, "o tipo adequado de impermeabilização a ser empregado na construção civil deve ser determinado segundo a solicitação imposta pelo fluido nas partes construtivas que requeiram estanqueidade".

No caso da solicitação em questão ela pode acontecer imposta por quatro maneiras diferentes: a) pela água de percolação; b) pela água de condensação; c) pela umidade do solo e d) pelo fluido sob pressão unilateral ou bilateral.

A NBR 9575:2010 aumenta seu alcance e também determina que o projeto de impermeabilização cuide de: 
a) evitar a passagem de fluidos e vapores nas construções, pelas partes que

requeiram estanqueidade, podendo ser integrados ou não outros sistemas construtivos, desde que observadas normas específicas de desempenho que

proporcionem as mesmas condições de estanqueidade;

b) proteger os elementos e componentes construtivos que estejam expostos ao

intemperismo, contra a ação de agentes agressivos presentes na atmosfera;

c) proteger o meio ambiente de agentes contaminantes por meio da utilização de sistemas de impermeabilização;

d) possibilitar sempre que possível acesso à impermeabilização, com o mínimo de intervenção nos revestimentos sobrepostos a ela, de modo a ser evitada, tão logo sejam percebidas falhas do sistema impermeável, a degradação das estruturas e componentes construtivos. (NBR 9575,2010).

O trabalho de impermeabilização é classificado quanto

a) ao sistema, se é rígido ou flexível (elástico);

b) se é pré-fabricado ou moldado no local (membranas);

c) se são aderentes ou não (as lajes);

d) se são armadas ou não;

e) se são protegidas ou expostas.

Em relação "as impermeabilizações rígidas elas são feitas com argamassa de cimento, areia e aditivos impermeabilizantes e sua grande desvantagem é que elas trincam acompanhando as trincas oriundas da base mal executada" (SANTOS, 2014:10, 2021).

Por sua vez, "as impermeabilizações elásticas têm sua grande vantagem de acompanhar os movimentos da base sem se romperem. São feitas com mantas pré-fabricadas ou com elastômeros dissolvidos e aplicados no local, em forma de pintura" (SANTOS, 2014:10, 2021).

A norma da ABNT NBR 9952 "Manta Asfáltica para Impermeabilização", estabelece os requisitos necessários para utilização de mantas asfálticas, recurso usado na maioria das obras.

É interessante que na entrega da obra pronta, seus usuários sejam alertados para uso correto das áreas que tenham passado pela impermeabilização para evitar, por exemplo, que sejam feitos furos em pisos de cobertura, o que compromete o serviço feito na impermeabilização. 
INFILTRAÇÕES - Nem sempre só pelo aparecimento de água já se pode deduzir a origem de uma manifestação patológica, pois a água flui de acordo com a gravidade e pode percolar dependendo do tipo de material.

Para Deutsch $(2011: 150,2021)$ "dos vícios redibitórios, o que provoca maiores reclamações, e é dos mais difíceis de se determinar, são aqueles oriundos de águas".

Neste caso, o uso da expressão vícios redibitórios se refere a falhas ou defeitos ocultos existentes no local analisado.

Continuando, Deutsch argumenta que

a água que afeta as superfícies situadas longe da pressão hidrostática do terreno, pode ser subdividida em:
a) provocada pela chuva;
b) pela ação capilar;
c) pela tensão superficial;
d) pela pressão do ar;
e) introduzida pelas forças de vento;
f) resultante de vazamentos nas redes (2011:150).

"As manifestações patológicas ocasionadas pela umidade são muito comuns no mundo da construção e estas podem gerar danos elevados, gerando gastos enormes em recuperação e reparo, que poderiam ser evitados com medidas simples preventivas". (SANTOS, 2014:11, 2021)

\section{CONCRETO ARMADO: CONSTITUIÇÃO E DETERIORIZAÇÃO}

Uma definição simplória de concreto é que se trata de uma mistura composta envolvendo cimento, água, areia (às vezes chamada de agregado miúdo) e pedra (chamada de brita ou agregado graúdo), feita manualmente com enxada e pá ou usando uma betoneira. Com a devida proporcionalidade entre esses elementos nessa mistura, obtém-se uma massa flexível que ao endurecer se transforma em um tipo de produto duro, semelhante a uma pedra na consistência e bem resistente.

O importante é que se transforme em uma massa homogênea. Para tornar essa massa ainda mais resistente à tração e à compressão, é incluída na mistura certa estrutura de aço, uma espécie de barra feita da mistura de ferro e carbono 
que se transforma em liga metálica, muito resistente que pode vir a ser forjada e modelada.

Juntando na proporção certa, o simples concreto com essa liga de aço, tem-se o chamado concreto armado, geralmente utilizado em fundações, lajes e vigas.

O concreto é, portanto, uma mistura de itens que, unidos, resultam num
material extremamente resistente e durável. Sua composição é
de cimento, areia (agregado miúdo), pedra ou brita (agregado graúdo)
e água. Âs vezes, também pode haver o acréscimo de outros
itens, como aditivos impermeabilizantes, aceleradores ou
retardadores de secagem do concreto, ou ainda outros tipos de
aditivos, para enriquecer o concreto de acordo com as necessidades
do projeto. Define-se como concreto armado a estrutura de concreto
que tenha em seu interior uma armadura feita com aço. (DECOR,
2021)

$\mathrm{Na}$ procura por mais resistência acrescentam-se na massa do concreto os aditivos químicos. São importantes os procedimentos e a dosagem correta na adição, porque essa união dos materiais redobra a resistência da estrutura. 0 concreto armado suporta melhor o peso que vier a ter sobre ele, enquanto a liga de aço não permite que a estrutura ceda, ou como se diz popularmente "embarrigue".

A proporção dos materiais precisa ser cuidadosamente equilibrada, com precisão nas quantidades de cada tipo de elemento acrescentado à massa. Os elementos que compõem o concreto armado transferem a ele a característica de tratar-se de material não inerte, ou seja, um material que durante sua vida útil pode sofrer alterações oriundas dos próprios ingredientes que o constituem.

Esses componentes em contato com elementos externos como ácidos, sais, gases, vapores e micro-orgânicos sofrem os efeitos que podem ocasionar os chamados problemas patológicos.

No entender do engenheiro Piancastelli, professor da Universidade Federal de Minas Gerais, "muitas vezes, dessas interações resultam anomalias que podem comprometer o desempenho da estrutura, provocar efeitos estéticos indesejáveis ou causar desconforto psicológico nos usuários". (AECweb:1, 2021)

Só quando o desempenho da estrutura está ameaçado ou comprometido é que ficam caracterizadas as 'enfermidades' do concreto ou da estrutura, que podem ser congênitas - nascem com a estrutura - ou são adquiridas ao longo de sua vida, devido à ação direta 
de inúmeros agentes externos, incluindo usuários, ou ainda fenômenos físicos, entre eles, choques, terremotos, incêndios, enchentes, explosões, recalques e variações de temperatura. (PIANCASTELLI in AECweb:1, 2021)

Em tópicos anteriores já foi verificado que para se descobrir as causas que dão origem ao fenômeno patológico é preciso uma análise criteriosa da obra. A profilaxia ideal é a observação sobre critérios e recomendações durante a elaboração do projeto e mesmo a execução da obra, mas se o problema não pode ser evitado, então a presteza do diagnóstico é fundamental para evitar perder a estrutura ou parte dela.

Muitas das doenças estruturais não se manifestam claramente ou são encobertas por outras, podendo passar despercebidas. Portanto, quanto mais criteriosa e aprofundada for a fase avaliativa, maiores serão os índices de acerto e eficiência da solução indicada (Visoto apud SACHS, 2015:42, 2021).

"Nos últimos anos as normas vêm incorporando essas medidas mais intensamente - critérios de durabilidade, que se fundamentam predominantemente nos mecanismos de deterioração do concreto (expansão e corrosão) e do aço (corrosão)". (PIANCASTELLI in AECweb:1)

Evidentemente, existem vários fatores ou causas, que podem afetar a durabilidade e resistência do concreto armado. Agentes naturais, embora de forma gradual, colaboram com essa perda do seu vigor estético, estrutural e funcional e são grandes responsáveis pelo envelhecimento do concreto.

A umidade relativa, vento, poluição, agressividade da água e temperatura, também colaboram no processo gradativo de degradação da estrutura. Existem diversos fatores que ocasionam diferentes formas de degradação, porém se convencionou considerar como principais tipos as seguintes causas: mecânicas, físicas e químicas.

Os processos principais que causam a deterioração do concreto podem ser agrupados, de acordo com sua natureza, em mecânicos, físicos e químicos [...] Os processos de degradação alteram a capacidade do material desempenhar as suas funções, e nem sempre se manifestam visualmente. Os três principais sintomas que podem surgir isoladamente ou simultaneamente são: a fissuração, o destacamento e a desagregação (LAPA, 2008: 9). 


\section{CAUSAS MECÂNICAS}

Como possíveis causas mecânicas são apontadas impactos ocasionados nas vias e estradas públicas, em viadutos, pontes, garagens, devido ao choque que acontece com veículos automotores. Também são apontados o recalque diferencial das fundações e a ocorrência de acidentes não previstos, tipo inundações; explosões, terremotos, etc.

Além de comprometer a capacidade resistente da estrutura a deterioração por causas mecânicas, facilita a entrada de agentes agressivos na estrutura danificada, principalmente quando o concreto e a armadura ficam expostos devido ao impacto das solicitações. Muito comum em viadutos, pontes, garagens e guarda-corpo (SANTOS, 2012:11, 2021).

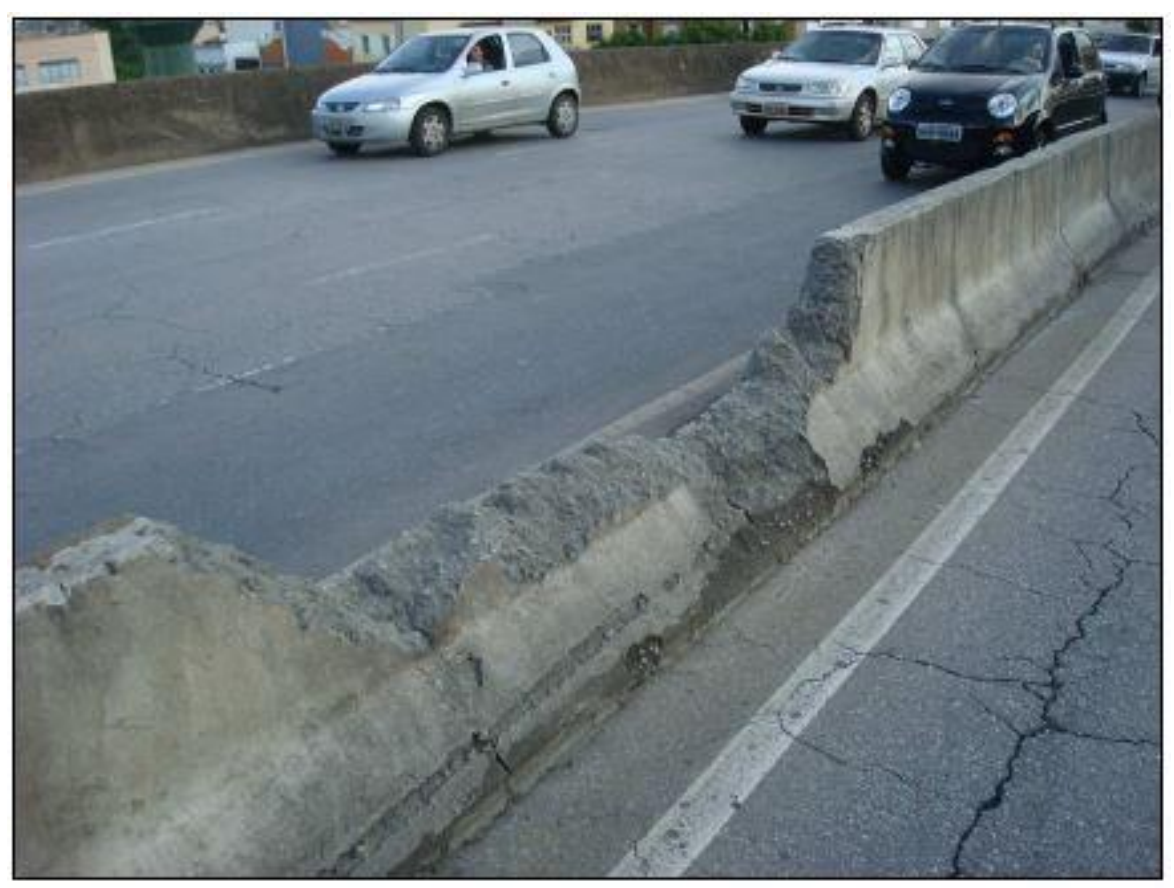

Fig. 1. Guarda-rodas rompido por batida de veículos em viaduto de Belo Horizonte (MG). Fonte: (SANTOS, 2012:11, 2021)

\section{CAUSAS FÍSICAS}

Souza e Ripper (1998) entendem que as causa físicas intrínsecas ao processo de deterioração da estrutura são resultantes da variação extrema da temperatura, da ação do vento, da água (sob a forma de chuva, gelo e umidade) e do fogo. Um exemplo é a Abrasão, processo que causa o desgaste superficial do concreto diminuindo sua funcionalidade, em pisos industriais, pavimentos 
rodoviários, estacionamentos, pontes e calçadas, que pode ocorrer até pela ação do vento.

Normalmente é resultante de fricção constante ou atrito em ambiente seco, (esfregamento), comum em locais de movimentação de cargas, tráfego de pessoas e veículos com rodas de aço ou borracha rígida, que provoca a perda de material do piso, transformando-o em pó.

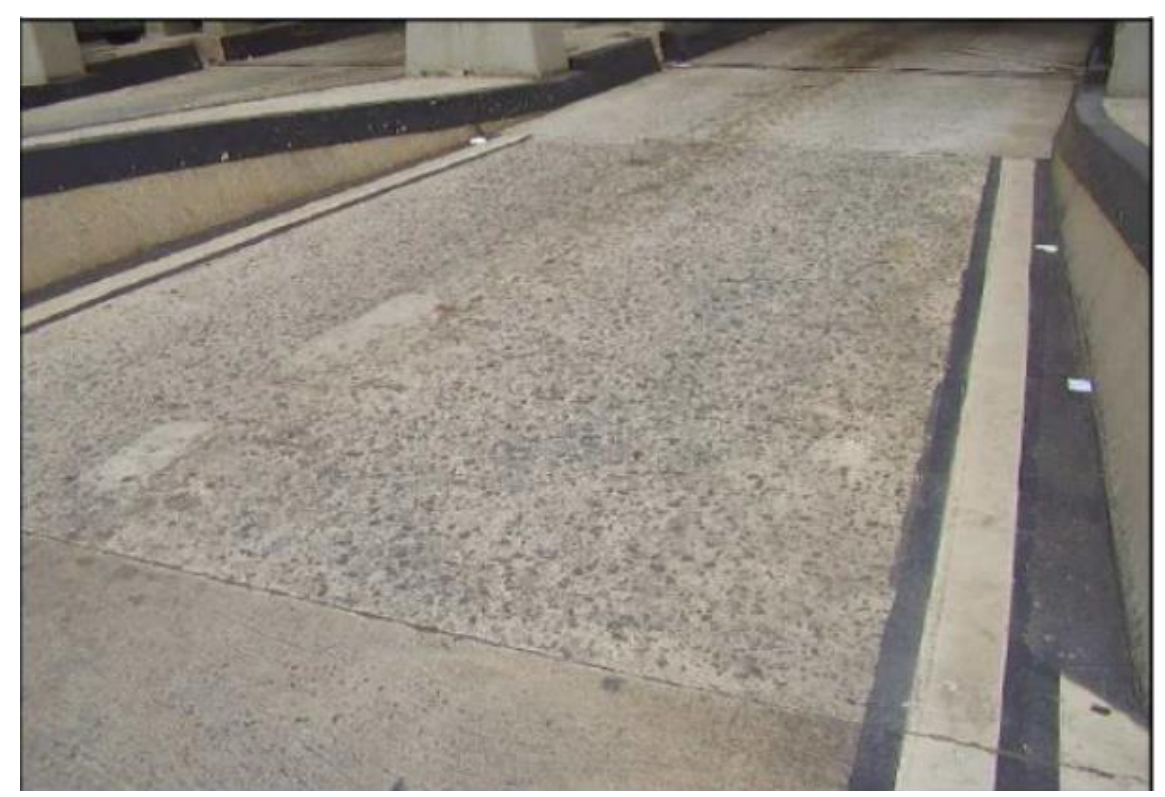

Fig. 2. Desgaste superficial por abrasão em pavimento de concreto. Fonte: (SANTOS, 2012:14, 2021)

\section{CAUSAS QUÍMICAS}

Já se constatou que a degradação química do concreto acontece pelo efeito de causas externas à estrutura, como a reação de agentes externos perante elementos que constituem o próprio cimento e por causas internas, no caso aquelas que ocorrem em casos de reação álcali-agregado, ou pela formação de compostos que levam o cimento a expandir-se, entre outras.

Só em caso de exposição rápida e pouco usual, principalmente quando os ácidos são fracos, é que o concreto resiste perante as soluções ácidas em sua pasta de cimento.

Em situação contrária o resultado são severas deteriorações na massa composta do concreto armado, chegando até à própria decomposição química da estrutura. Como efeitos das reações químicas nocivas a ele, se classificam a fissuração e o destacamento da sua base, a diminuição da resistência, além do aumento das condições de porosidade e permeabilidade. 
Entre as causas químicas e a atuação na degradação do concreto são citadas as ações por ataques de sulfatos, dos quais destacam-se o Sulfato de Sódio (Na2SO4), o Sulfato de Magnésio ((MgSO4), Sulfato de Amônia (NH4SO4), Sulfato de Potássio (K2SO4) e o Sulfato de Cálcio (CaSO4).

Também a hidratação dos componentes do cimento ( $\mathrm{MgO}$ e $\mathrm{CaO})$, que segundo Souza e Ripper (1998),

o óxido de magnésio ( $\mathrm{MgO}$ ), um dos constituintes do cimento, poderá ser expansivo quando estiver na forma de pericálcio, que irá se hidratar de maneira muito lenta após o endurecimento do cimento (e do concreto), resultando no aumento do volume e consequente fissuração do concreto.

E a reação álcali=agregado, fenômeno do concreto que resulta em problemas patológicos tanto em nível da estrutura como operacional. As estruturas de concreto armado normalmente sujeitas às reações álcali-agregado são aquelas situadas em ambientes úmidos, tais como: pilares de pontes, blocos de fundação, barragens, estruturas marítimas, etc.

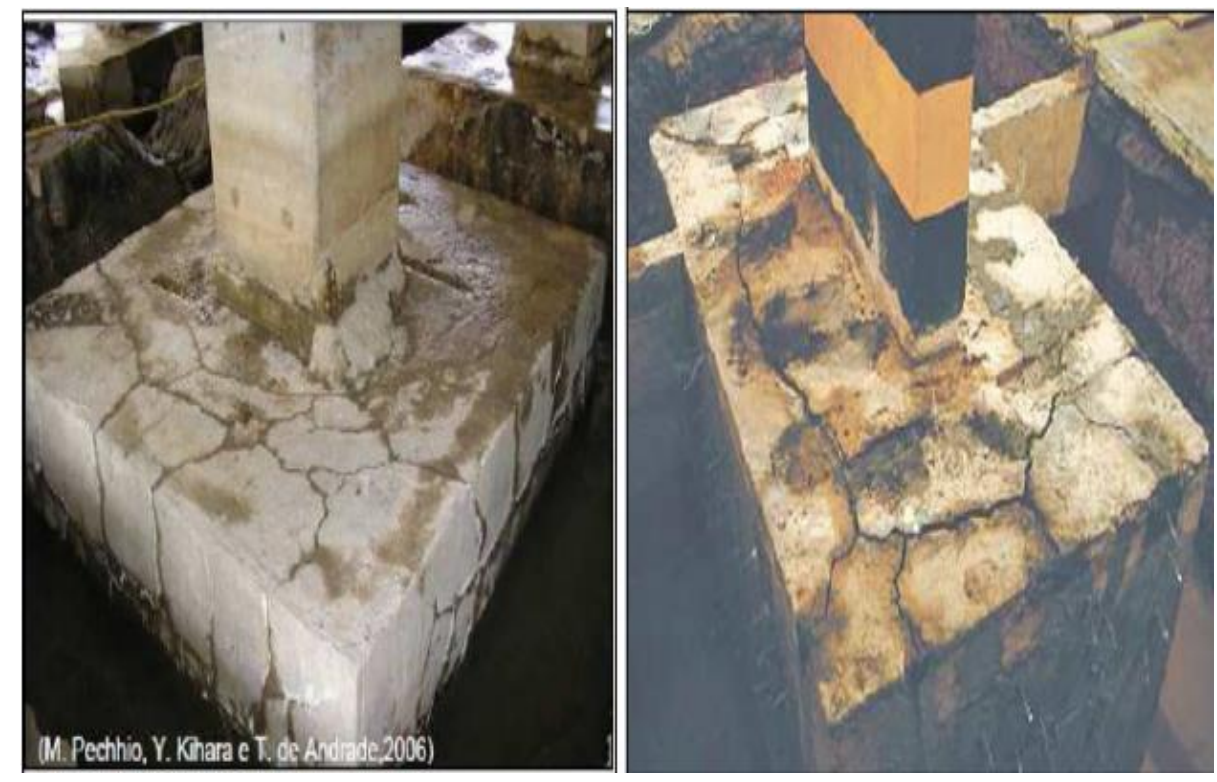

Fig. 3. Reação álcali-agregado em blocos de fundação de edifícios em Recife (PE) Fonte: SANTOS, 2012:33.

Em resumo, o que se pode dizer é que as edificações de concreto armado, como em geral qualquer estrutura, estão expostas a diversos tipos de complexos processos que podem ocasionar a degradação, alterando sua capacidade funcional, durabilidade, resistência e estética. 
Embora nem todos os processos destrutivos tenham imediata manifestação visual, alguns fatores ou sintomas podem aparecer de forma isolada ou simultânea, como indicativos dos problemas estruturais.

São as chamadas fissura, trinca, rachadura e fenda causadas por tensão dos materiais e classificadas conforme a abertura apresentada, fator indicativo da gravidade de cada tipo.

\title{
FISSURA
}

De acordo com a NBR 9575\2003, "fissura é a abertura ocasionada por ruptura de um material ou componente, com abertura inferior ou igual a 0,5mm".

Trata-se, portanto, de um estágio inicial de abertura superficial, geralmente longa e estreita, que atinge pintura, massa corrida, cimento queimado e azulejos. A fissura é considerada de pouca gravidade, sem oferecer perigo, quando não alcança a estrutura. Mas é importante observar sua evolução com o tempo, pois se ela deixar de ser estável pode evoluir até para uma rachadura ou fenda.

\begin{abstract}
As fissuras podem ser classificadas como ativas (variação da abertura em função de movimentações hidrotérmicas ou outras) ou passivas (abertura constante), ou seja, para a especificação de um correto tratamento, é de vital importância que se verifique se a fissura analisada é ativa (viva ou instável) ou inativa (morta ou estável). São chamadas de ativas, as fissuras que apresentam variação de abertura, e de inativas aquelas em que tal variação não ocorre. Tal verificação é feita, geralmente, através da utilização de "selos" rígidos, que são gesso ou plaquetas de vidro coladas, que se rompem caso a fissura apresente variação de abertura, ou através da medição direta (fissurômetro) dessa variação (PIANCASTELLI, 1997, 2021).
\end{abstract}

\section{TRINCA}

Enquanto para a NBR 9575\2003, "trincas são aberturas ocasionadas por ruptura de um material ou componente com abertura superior a $0,5 \mathrm{~mm}$ e inferior a 1,0mm", a NBR 15.575:2013 apresenta as trincas como: "expressão coloquial qualitativa aplicável a fissuras com abertura maior ou igual a $0,6 \mathrm{~mm}$ ".

A abertura da trinca tem aparência mais profunda e acentuada do que as fissuras e oferece maior perigo, pois pode afetar a segurança dos elementos da estrutura da edificação, visto que onde ela ocorre promove a ruptura do elemento separando-o em duas partes. 
Devido ao perigo que oferece e em decorrência da dificuldade em ser avaliada a olho nu, sua real qualificação deve ser feita com o uso de equipamento especializado.

\section{RACHADURA}

As rachaduras são perigosas, pois assim como as trincas elas também promovem a separação entre partes. Aparecem como grandes aberturas, profundas e muito pronunciadas, que se percebe com absoluta clareza.

$\mathrm{Na}$ rachadura as manifestações da natureza como vento, água e luz entram facilmente atestando o tamanho de sua abertura e o dano da estrutura. Por se tratar de uma abertura com espessura acima de $3 \mathrm{~mm}$ e muito acentuada requer imediata atenção em relação a seu reparo.

\section{FENDA}

A fenda, às vezes também chamada de brecha, é a mais grave demonstração de sintoma do processo destrutivo de uma edificação. Tem causas não visíveis (solapamento do subsolo) que às vezes se ocultam por muito tempo.

Manifestam-se de repente, com a abertura de um enorme buraco que pela largura e profundidade podem ocasionar graves acidentes, como por exemplo, a abertura de uma cratera no asfalto com possibilidade de sugar até mesmo um veículo.

\section{CONSIDERAÇÕES FINAIS}

Num mercado em constante atualização, a construção civil no Brasil vive em meio a exigência pelo tempo da obra, com obrigatoriedade ao atendimento às normas de fiscalização, prensada pelo custo dos materiais e pela dificuldade de preservar a qualificação técnica na escolha dos seus operadores.

Dá-se muita importância a necessidade de redução de custos e garantir a satisfação do usuário final da obra, com o cumprimento de prazos pré- 
estabelecidos, mas se descuida da melhoria nos processos de execução das estruturas e na garantia de qualidade e durabilidade do material utilizado.

A observação sobre a variedade de manifestações patológicas encontradas nas construções erguidas com a utilização do concreto armado quer sejam em obras públicas ou particulares, despertou 0 interesse no aprofundamento de estudos sobre as causas dessas anomalias.

O interesse inicial levou ao estudo detalhado, através de consulta a variada bibliografia específica da área, para adquirir mais conteúdo sobre as origens e formas das manifestações patológicas nessas estruturas. Principalmente para saber sobre esses processos destrutivos com intenção de evitar o problema na futura vida profissional.

Através dessa consulta bibliográfica ampliou-se o conhecimento sobre noções de patologia, durabilidade de materiais, possíveis agressores se usados indiscriminadamente na limpeza da obra concluída, e outros aspectos que podem surgir no desenvolvimento de um trabalho e gerar uma anomalia perigosa para a edificação.

Considerando que o Código de Defesa do Consumidor tende a atuar como regulador da responsabilidade civil do construtor com a obra, para evitar as demandas judiciais decorrentes de insatisfação com o imóvel no caso da entrega do bem não estar dentro do padrão acertado entre as partes.

Entende-se que existem normas estipuladas para orientação no bom desempenho na construção, requisitos que se atendidos pelos profissionais envolvidos no projeto revertem em durabilidade da obra e satisfação do cliente.

Considera-se, pois, que todos os elos da cadeia produtiva da indústria da construção, desde os projetistas, fabricantes, construtores, incorporadores e consumidores, incluindo os operários das etapas básicas embora primárias, possuem respectivas responsabilidades e devem possuir qualificação técnica compatível com a função a ser exercida.

Considera-se, também, que é grande a oferta do tipo de material disponível, cuja variedade se comprova tanto na quantidade como na qualidade, um fator limitador devido ao alto custo de bens mais duráveis, o que acarreta muita responsabilidade para o profissional nessa escolha.

Conclui-se, então, que se antes o objetivo se resumia a apenas saber fazer um diagnóstico preciso a respeito dos problemas patológicos, agora, após 
conhecer sobre suas causas e conceber medidas preventivas, o entendimento é que para evitar esses desgastes existe a necessidade de controle rigoroso em todas as fases da obra, desde a elaboração do projeto, na escolha de materiais, na utilização adequada deles segundo padrões de fabricação e orientação sobre cuidados para manutenção das estruturas.

É preciso constante aprimoramento quanto a novas técnicas disponíveis no mercado da construção objetivando, sempre, a melhoria na qualidade da obra e a valorização profissional. 


\section{REFERÊNCIAS}

ABNT, ASSOCIAÇÃO BRASILEIRA DE NORMAS TÉCNICAS. NBR 9574: Execução de Impermeabilização. Rio de Janeiro, 2008. >Acesso em $29 / 09 / 2021$

ABNT, ASSOCIAÇÃO BRASILEIRA DE NORMAS TÉCNICAS. NBR 9575: Impermeabilização - seleção e projeto. Rio de Janeiro, 2010. >Acesso em 29/09/2021

ABNT, ASSOCIAÇÃO BRASILEIRA DE NORMAS TÉCNICAS. NBR 9952: Manta asfáltica para impermeabilização. Rio de Janeiro, 2007. >Acesso em 29/09/2021

AECweb - Desempenho da estrutura - Patologia + Estrutura - Disponível em: Disponível em: https://www.aecweb.com.br/revista/materias/patologias-doconcreto/6160 >Acesso em 02/10/2021

BOTELHO, M.H.C.; MARCHETTI, O. Concreto armado eu te amo. Edgar Blucher: São Paulo, 2004. >Acesso em 03/10/2021

CÁNOVAS, M. F. Patologia e terapia do concreto armado. Tradução e adaptação de: Maria Celeste Marcondes et al., coordenação técnica L. A. Falcão Bauer. Editora PINI: São Paulo, 1988. >Acesso em 03/10/2021

CAVACO - Concreto armado - Patologia + Estrutura - Disponível em: CAVACO, Jonas Rodrigo Zimmermann. Patologias nas estruturas de concreto armado. Universidade Regional de Blumenau: Santa Catarina, 2008. >Acesso em 05/10/2021

DEUTSCH - Análise - Patologia + Estrutura - Disponível em: DEUTSCH, Simone Feigelson. Perícias de engenharia: a apuração dos fatos. LEUD: São Paulo, 2011. >Acesso em 06/10/2021

DECOR - Concreto - Patologia + Estrutura - Disponível em: http://construindodecor.com.br/concreto-armado/\#forward >Acesso em 10/10/2021

DIAS, Luís Andrade de Mattos. Aço e arquitetura: estudo de edificações no Brasil. ZIGURATE Editora: São Paulo, 2001. >Acesso em 06/10/2021 
EVOLUÇÃO - Estabilidade e Segurança - Patologia + Estrutura - Disponível em: https://alcancejr.com.br/evolucao-da-engenharia-civil// >Acesso em 27/09/2021

GRANDISKI, Paulo. Problemas Construtivos. Apostilas, 2011. >Acesso em 06/10/2021

HELENE, Paulo R. do Lago. Corrosão em armaduras para concreto armado. Editora PINI: São Paulo, 1986. >Acesso em 06/10/2021

HUGON, A. Técnicas de construção. HEMUS Imagem Digital: São Paulo, 2004. >Acesso em 10/10/2021

LAPA, J. S. Patologia, recuperação e reparação das estruturas de concreto armado. Universidade Federal de Minas Gerais: Belo Horizonte, 2008. Disponível em: https://docente.ifrn.edu.br/valtencirgomes/disciplinas/patologiae-rec-de-estrutura/patologia-e-recuperacao-de-estrutura-monografia $>$ Acesso em 15/10/2021

Manual Prático para reparo, reforço e proteção das estruturas de concreto. Editora PINI: $2^{\underline{a}}$ ed. São Paulo, 1992. >Acesso em 10/10/2021 $\overline{31 / 05 / 2021 .}$

MICHAELIS. Dicionário Brasileiro da Língua Portuguesa > Acesso em

NÁPOLES NETO, Antonio Dias Ferraz. História das fundações. In: $\mathrm{HACHICH}$; FALCONI; SAES; FROTA; CARVALHO; NIYAMA (Eds). Fundações: teoria e prática. Editora PINI: 2ª ed., São Paulo, 1998. p. 17-34. >Acesso em $15 / 10 / 2021$

OLIVEIRA E. V., GALHANO F, PEREIRA B. Construções Primitivas em Portugal. Instituto da Alta Cultura - Centro de Estudos de Etnologia: Lisboa, 1969. > Acesso em 31/05/2021.

PIANCASTELLI, Élvio M. - Patologia, Recuperação e Reforço de Estruturas de Concreto Armado - Ed. Departamento de Estruturas da EEUFMG - 1997 - 160p. >Acesso em 10/10/2021 
RIELI. Engenharia Civil. Disponível em:

www.rieli.com.br/profissao/pb33.htm. >Acesso em 10/10/2021

RIPPER, Ernesto. Como evitar erros na construção. PINI: São Paulo, 1984. >Acesso em 10/10/2021

SACHS, A. Tratamento intensivo. Téchne: 220, p. 40-44, São Paulo, julho de 2015. >Acesso em 19/10/2021

SANTOS - Deterioração das estruturas de concreto - Patologia + Estrutura Disponível em: www.bibliotecadigital.ufmg.br >Acesso em 12 Agosto 2021.

SANTOS, Silmara. Patologia das Construções. ESPECIALIZE - Revista on line IPOG - 7 ${ }^{a}$ ed. № 7. Vol. 1. Goiania: GO. Julho, 2014. >Acesso em 12 Agosto 2021.

SOUZA, Vicente Custódio Moreira de. \& RIPPER, Thomaz. Patologia, recuperação e reforço de estruturas de concreto. Editora PINI: São Paulo, 1998. >Acesso em 11/10/2021

SOUZA, M.F. Patologias ocasionadas pela umidade nas edificações. $\overline{\text { Escola }}$ de Engenharia da UFMG, 2008. >Acesso em 11/10/2021

THOMAZ, Ercio. Trincas em Edifícios: causas, prevenção e recuperação. PINI: São Paulo, 1989. >Acesso em 10/10/2021

VARGAS - Técnicas locais - Patologia + Estrutura - Disponível em:

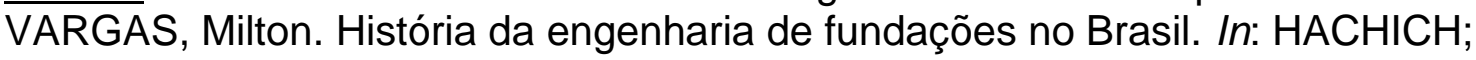
FALCONI; SAES; FROTA; CARVALHO; NIYAMA (Eds). Fundações: teoria e prática. Editora PINI: 2ª ed., São Paulo, 1998. p. 34-50. Acesso em 27/09/2021

VERÇOZA, Enio José. Impermeabilização na Construção. Editora $\overline{\text { SAGRA }}$ : Porto Alegre, 1985. >Acesso em 10/10/2021 